\title{
Effectiveness of Home and Community Exercise Interventions in Improving Indices of Adiposity and Health Outcomes in Adults Living With HIV: a Protocol for a Systematic Review.
}

Jeannine Anyingu Aminde ( $\nabla$ jeannine.atemepseaminde@griffithuni.edu.au )

Griffith University - Gold Coast Campus https://orcid.org/0000-0003-3149-6494

Neil Harris

Griffith University School of Medicine

Caroline Thng

Gold Coast University Hospital

Ben Desbrow

Griffith University School of Allied Health Sciences

\section{Protocol}

Keywords: Adiposity, home exercise, fat distribution, HIV

Posted Date: February 9th, 2021

DOl: https://doi.org/10.21203/rs.3.rs-186428/v1

License: (c) (1) This work is licensed under a Creative Commons Attribution 4.0 International License.

Read Full License 


\section{Abstract}

Background: Disorders of adipose distribution in people living with the human immunodeficiency virus (HIV) have been associated with significant metabolic derangements that increase their risk of cardiovascular and other chronic diseases. Systematic reviews focusing on centre-based supervised exercise interventions demonstrate that these interventions improve adipose distribution in people living with HIV (PLWH). However, there is need to examine the effectiveness of more flexible home/community self-managed exercise. The aim of this review will be to synthesize existing evidence on the effectiveness of home and community exercise interventions to improve adiposity indices in PLWH.

Methods: The following databases will be searched from inception; PubMed, Embase, Scopus, Cumulative Index to Nursing and Allied Health Literature, Physiotherapy Evidence Database, SPORTDiscus, Cochrane Central Register of Controlled Trials, Cochrane Database of Systematic Reviews and Clinicaltrials.gov. In addition, reference lists searching and forward citation searching will be performed. Screening of studies and data extraction will be conducted by two independent reviewers using a pre-established checklist and no language restrictions will be applied. The quality of included studies will be evaluated with the Cochrane Effective Practice and Organisation of Care Risk of bias tool for controlled and uncontrolled before-after studies. A random-effects meta-analysis will be used to pool effect estimates for primary outcomes (measures of total body adiposity, adipose distribution, and regional adiposity). However, if pooling is deemed inappropriate due to substantial differences between studies, a narrative synthesis will be performed. This protocol is written according to the Preferred Reporting Items for Systematic reviews and Meta-analysis Protocols 2015 statement (see Additional file 1).

Discussion: This review shall provide evidence to support or disapprove the prescription of self-managed home exercise interventions in a particularly vulnerable population. We will equally explore the potential impact of technology in improving adherence. Our findings could help guide clinicians involved in the care of PLWH in prescribing exercise and inform the design of future trials and research.

Systematic review registration: This protocol was submitted with the International Prospective Register of Systematic Reviews (PROSPERO) on 11/01/2021.

\section{Introduction}

\section{Rationale}

Disorders of adipose distribution in people living with HIV (PLWH) have garnered fresh interest in recent times. This is due to the advent of antiretrovirals which have both improved survival (1) and appear to induce weight gain $(2,3)$.

Inflammatory and immune pathways (even in the virally suppressed) accentuated by antiretroviralinduced cytokine dysregulation are believed to provoke the expansion of metabolically active adipose 
deposits and adipose redistribution $(4,5)$. The consequences of which include obesity, insulin resistance, dyslipidaemias, atherogenesis $(4,6)$ and oncogenesis $(7)$. Importantly, these HIV-related factors are aggravated by various lifestyle factors which are significantly more prevalent in the HIV population such as alcohol and substance abuse disorders, smoking, hepatitis $B$ and hepatitis $C(8,9)$. Hence, the increased risk of strokes, myocardial infarctions, diabetes mellitus and certain cancers in $\operatorname{PLWH}(8,10$, 11). Therefore, strategies that address adiposity disorders and their associated cardiometabolic risk could help mitigate the burden of varied comorbidities in PLWH as they age.

Physical activity reduces inflammation in chronic HIV and is considered a corner stone in the management of HIV-associated cardiometabolic derangements $(4,12)$. Various clinical trials have demonstrated that exercise programs incorporating aerobic and strength training are safe (13-15) and efficacious $(13,16,17)$ in correcting adiposity derangements and dyslipidaemias in PLWH. In addition to these benefits, aerobic exercise for PLWH equally improves cardiorespiratory function and quality of life $(13,17)$, while resistance exercise improves muscle strength $(14,18)$, immune function $(19)$ and muscle mass (14).

However, the transferability of these benefits to everyday settings remains a challenge. Studies on exercise interventions in PLWH record dropout rates as high as $29 \%(20)$. While professional supervision appears to reduce dropout (20), exercising with an exercise physiologist, sports therapist, physiotherapist or other professional in an exercise facility is resource intensive. This raises issues of accessibility and long-term sustainability in a population that already faces more frequent hospital visits and higher health care costs (8). There is therefore the need to assess more exercise options.

Some reviews demonstrate the benefits of home-exercise programs as a viable alternative to centrebased exercise in other chronic conditions $(21,22)$. Roos and colleagues found that a home exercise walking program without supervision reduced waist-to-hip ratio and ischaemic heart disease risk in PLWH (24). Similarly, a second trial found comparable improvements in body composition for persons who exercised at home without supervision and those who followed a supervised program (25). On the other hand, Bonato and colleagues reported significant reductions in fat mass of home exercises only if supported with a mobile application (26). It is possible that prescribed self-managed exercise at home or in the local community with or without (mobile/computer) technology support could prove useful in PLWH. To date, no study has synthesized the evidence on home and community-based exercise interventions in PLWH.

Therefore, the aim of this review is to systematically synthesize all available evidence on the effectiveness of home and community exercise interventions that have minimal or no supervision in improving adiposity indices and health outcomes in people living with HIV.

\section{Objectives}

i. To determine the efficacy of home and community exercise programs in improving indices of adiposity in adults living with HIV. 
ii. To ascertain the impact of technology-assisted remote support (that is through phone, computer, or other smart devices) in adherence to home and community exercise programs in adults living with HIV.

\section{Methods}

\section{Eligibility criteria}

\section{A. Population of interest}

HIV positive male or female adults, 18 years and older, at all stages of infection (CD4, viral loads), with or without comorbidities in any part of the world.

\section{B. Intervention}

Prescribed exercise performed at home or in the community of at least four-week duration, with minimal or no supervision. The program must include either an aerobic component or resistance component.

We will consider "prescribed exercise" to be a structured physical activity plan made available to participants with specified type, intensity, duration, and frequency of activity, accompanied by some form of monitoring (such as an exercise diary).

"Community" will refer to local public settings and outdoor spaces that are freely accessible, such as parks and public recreational facilities (see Table 1).

Table 1

CRITERIA AND DEFINITION OF HOME/COMMUNITY EXERCISE

\begin{tabular}{|lll|}
\hline Criterion & $\begin{array}{l}\text { HOME/COMMUNITY } \\
\text { MINIMALLY SUPERVISED }\end{array}$ & CENTRE-BASED SUPERVISED \\
\hline Supervision & $\begin{array}{l}\text { - Mostly self-managed. } \\
\text { - Instruction offered during less than half of } \\
\text { exercise time }\end{array}$ & $\begin{array}{l}\text { - Mostly supervised. } \\
\text { - Instruction offered during half } \\
\text { or more of exercise time }\end{array}$ \\
\hline Location & Home environment or local neighbourhood & $\begin{array}{l}\text { Within a specialised exercise } \\
\text { facility }\end{array}$ \\
\hline Equipment & Present or absent & $\begin{array}{l}\text { Specialised equipment designed } \\
\text { for exercise }\end{array}$ \\
\hline Eccessibility/cost & Accessible to the public at little or no cost & $\begin{array}{l}\text { Not routinely open to the public } \\
\text { Examples }\end{array}$ \\
$\begin{array}{l}\text { Within home, public outdoor spaces such } \\
\text { as parks, community centres, public } \\
\text { recreational facilities }\end{array}$ & $\begin{array}{l}\text { hospital clinics, exercise } \\
\text { laboratories, private practice, } \\
\text { physiotherapy clinics }\end{array}$ \\
\hline
\end{tabular}


We will exclude studies of interventions in a detention or prison facility, as well as those where the setting is not clearly reported and cannot be sourced from the authors.

"Minimal supervision" will be regarded as professional input (in-person or virtual) in the form of instruction during exercise sessions for less than half the total duration of exercise time. Remote observation through physical activity monitors or exercise logbooks will not be considered supervision. Professional support restricted to safety or compliance checks, reminders, counselling, or motivation will also not be considered supervision.

Aerobic exercise will be defined as any physical activity performed with the aim of strengthening the heart and lungs, that results in increased breath and heart rates. This will include (but not limited to): jogging, running, walking, swimming, stair climbing, stepping, rowing, jump rope, dancing, and cycling.

Resistance exercise will be defined as any physical activity performed with the aim of strengthening muscle, utilising muscle contractions against resistance aided by weights (free weights, weight stations amongst others) or unaided (resistance provided by body's own weight).

\section{Comparators}

We will compare home/community exercise outcomes to "before exercise" in single-group design or to control arms with no exposure/intervention, standard care, other types of exercise programs such as centre-based exercise (see Table 1), or other therapeutic modalities.

\section{Outcomes}

\section{Primary}

Our primary outcomes shall include the following measures (classification was adapted from previous work (27)):

\section{i. Total body adiposity}

- total fat mass

- percent body fat

- body mass index ((BMI = body weight in kilograms/(height in metres $\left.)^{2}\right)$

- fat mass index ((FMl = total fat mass in kilograms/(height in metres $\left.)^{2}\right)(28)$

- body adiposity index (BAI = ((hip circumference in centimetres $\left.\left.\left.) /(\text { (height in metres })^{1.5}\right)-18\right)\right)(29)$

ii. Body adipose distribution

- waist-to-hip ratio (WHR)

- waist-to-height ratio

- waist-to-thigh ratio 
- supine sagittal abdominal diameter (abdominal anteroposterior diameter in a supine person measured directly or by imaging) (27)

- waist circumference

iii. Regional adiposity

- skinfold thickness measurements

- visceral adipose tissue (VAT) volumes/mass

- regional fat percentages

- subcutaneous fat volumes/mass.

In this study weight will not be considered a primary outcome measure of adiposity because of its wellrecognized inability to account for body build and its susceptibility to changes in lean mass (27).

Secondary: In addition to the above primary outcomes, the following will be evaluated: changes in weight, metabolic parameters (fasting glucose, lipids), virologic outcomes (viral load, CD $4^{+} \mathrm{T}$ cells), physical activity levels (self-report or device measured), adherence to exercise program, muscle/lean mass, muscle strength, cardiorespiratory fitness, quality of life measures, psychological health measures, neurocognitive function, adverse events related to exercise.

\section{E. Study Characteristics}

Randomized control trials, non-randomized control trials, and uncontrolled single arm interventional studies published before 31st January 2021 will be included.

\section{Information sources}

We will search general databases (PubMed, PubMed Central, Embase and Scopus), databases specific to allied health (Cumulative Index to Nursing and Allied Health Literature (CINAHL), Physiotherapy Evidence Database (PEDro) and SPORTDiscus) and trial registries (Cochrane Central Register of Controlled Trials, Cochrane Database of Systematic Reviews and Clinicaltrials.gov).

Databases will be searched from inception up to 31st January 2021 for peer-reviewed articles and peerreviewed conference papers published or accepted for publication. Reference lists of the included studies and relevant systematic reviews will be manually back searched to identify any relevant articles. In addition, forward citation searching of included studies will be undertaken in Google Scholar and Scopus.

When full texts are unavailable or in the case of missing relevant data, the authors will be approached via email to obtain this information. No language restrictions shall be applied to our search. The services of a professional translator will be sought for articles that are not available in the English language.

\section{Search strategy and study selection}

The search strategy was designed by review authors in consultation with a professional librarian and pretested prior to the formal search. Key terms pertaining to "exercise", "HIV", "adiposity" and 
"interventional study" were included, see details in Table 2. Records retrieved will be exported to and managed in the EndNote referencing software. After elimination of duplicates, screening will be performed independently by two review authors. Studies with irrelevant titles will be excluded. Abstracts of the remaining studies will then be examined using pre-established inclusion checklist. Where additional information is required to determine eligibility, the reviewers will contact the authors concerned via email. Where there are several publications of the same study (such as a protocol paper cited in the principal article), the publications will be collated and considered together. When abstracts are deemed relevant or where eligibility is unclear, full texts will be obtained. Full texts will be assessed independently by two review authors. Any disagreements will be resolved through consensus or by the decision of a third independent reviewer. 
Table 2

PUBMED SEARCH STRATEGY

\begin{tabular}{|c|c|c|c|c|}
\hline \multirow{2}{*}{$\begin{array}{l}\text { Field } \\
\text { limits }\end{array}$} & \#1 & $\# 4$ & \#9 & $\# 12$ \\
\hline & title and abstract & $\begin{array}{l}\text { title and } \\
\text { abstract }\end{array}$ & full text & $\begin{array}{l}\text { title and } \\
\text { abstract }\end{array}$ \\
\hline \multirow[t]{7}{*}{$\begin{array}{l}\text { Keyword } \\
\text { query }\end{array}$} & \multirow[t]{6}{*}{$\begin{array}{l}\text { "human } \\
\text { immunodeficiency" } \\
\text { OR "human } \\
\text { immune } \\
\text { deficiency" OR HIV } \\
\text { OR "acquired } \\
\text { immune } \\
\text { deficiency" OR } \\
\text { "acquired } \\
\text { immunodeficiency" } \\
\text { OR "aquired } \\
\text { immunodeficiency" } \\
\text { OR "aquired } \\
\text { immune } \\
\text { deficiency" OR } \\
\text { "HIV/AIDS" }\end{array}$} & $\begin{array}{l}\text { exercis* OR } \\
\text { sport* OR } \\
\text { workout OR } \\
\text { physiotherapy } \\
\text { OR } \\
\text { kinesiotherapy } \\
\text { OR walking } \\
\text { OR jogging OR } \\
\text { running OR } \\
\text { swimming OR } \\
\text { bicycling OR } \\
\text { cycling OR } \\
\text { "weight-lifting" } \\
\text { OR dancing } \\
\text { OR "resistance } \\
\text { bands" OR } \\
\text { "home gym" }\end{array}$ & \multirow[t]{6}{*}{ 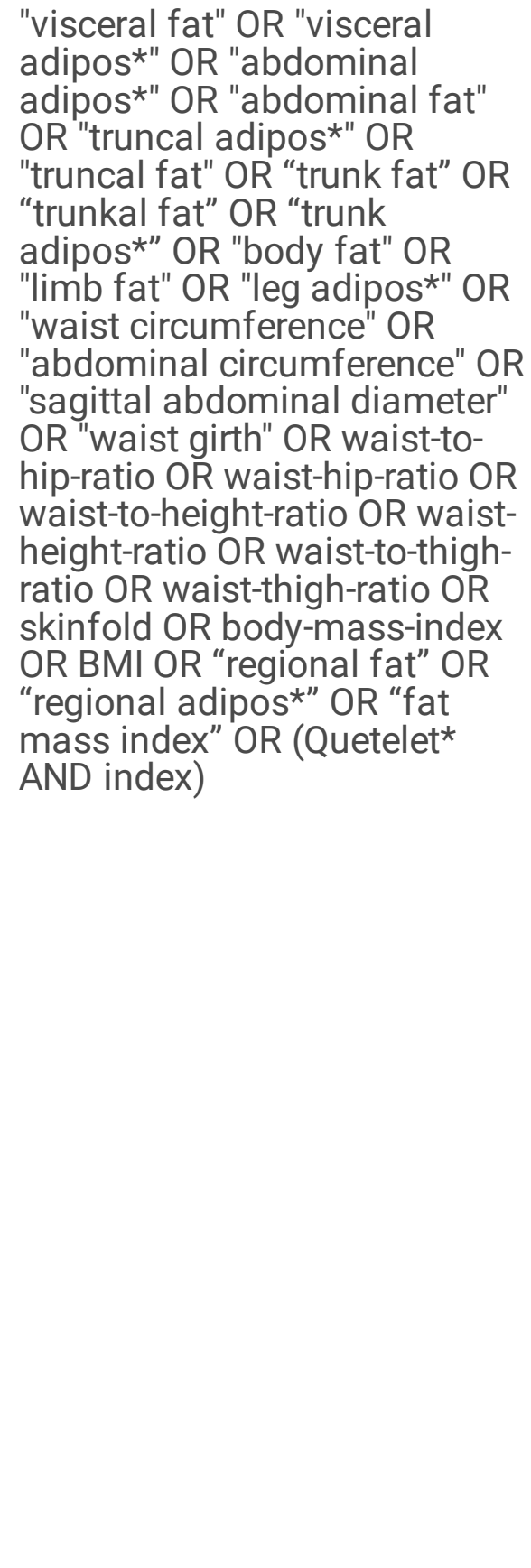 } & \multirow[t]{6}{*}{$\begin{array}{l}\text { Intervention` } \\
\text { OR } \\
\text { program* } \\
\text { OR trial }\end{array}$} \\
\hline & & $\begin{array}{l}\# 5 \\
\text { title and } \\
\text { abstract }\end{array}$ & & \\
\hline & & $\begin{array}{l}\text { (physical OR } \\
\text { aerobic OR } \\
\text { resistance) } \\
\text { AND (fitness } \\
\text { OR therapy OR } \\
\text { training OR } \\
\text { rehabilitation) }\end{array}$ & & \\
\hline & & \#6 & & \\
\hline & & $\begin{array}{l}\text { title and } \\
\text { abstract }\end{array}$ & & \\
\hline & & $\begin{array}{l}\text { (weight OR } \\
\text { endurance OR } \\
\text { strength OR } \\
\text { circuit) AND } \\
\text { training }\end{array}$ & & \\
\hline & \#2 & \#7 & \#10 & \#13 \\
\hline
\end{tabular}




\begin{tabular}{|c|c|c|c|c|}
\hline \multirow{2}{*}{$\begin{array}{l}\text { Field } \\
\text { limits }\end{array}$} & \#1 & \#4 & \#9 & \#12 \\
\hline & title and abstract & $\begin{array}{l}\text { title and } \\
\text { abstract }\end{array}$ & full text & $\begin{array}{l}\text { title and } \\
\text { abstract }\end{array}$ \\
\hline $\begin{array}{l}\text { Index } \\
\text { term } \\
\text { query }\end{array}$ & $\begin{array}{l}\text { "HIV"[Mesh] OR } \\
\text { "HIV Long-Term } \\
\text { Survivors"[Mesh] } \\
\text { OR "HIV Infections" } \\
\text { [Mesh] }\end{array}$ & $\begin{array}{l}\text { "Exercise" } \\
\text { [Mesh] OR } \\
\text { "Exercise } \\
\text { Therapy" } \\
\text { [Mesh] OR } \\
\text { "Sports"[Mesh] } \\
\text { OR "Exercise } \\
\text { Movement } \\
\text { Techniques" } \\
\text { [Mesh] }\end{array}$ & $\begin{array}{l}\text { "Body Composition"[Mesh] OR } \\
\text { "Body Weights and Measures" } \\
\text { [Mesh] OR "Adipose Tissue, } \\
\text { White"[Mesh] }\end{array}$ & $\begin{array}{l}\text { "Clinical } \\
\text { Trials as } \\
\text { Topic" } \\
\text { [Mesh] OR } \\
\text { "Clinical } \\
\text { Trial" } \\
\text { [Publication } \\
\text { Type] }\end{array}$ \\
\hline Combined & $\# 3$ = \#1 OR \#2 & $\begin{array}{l}\# 8=\# 4 \text { OR \#5 } \\
\text { OR \#6 OR \#7 }\end{array}$ & \#11 = \#9 OR \#10 & $\begin{array}{l}\# 14=\# 12 \\
O R \# 13\end{array}$ \\
\hline $\begin{array}{l}\text { Final } \\
\text { string }\end{array}$ & \multicolumn{4}{|c|}{ \#3 AND \#8 AND \#11 AND \#14 } \\
\hline
\end{tabular}

\section{Data extraction and management}

A pre-piloted data extraction form developed in Microsoft Excel by the authors will be used to extract information (see form attached (Additional file 2)). The primary outcome characteristics will be extracted by two independent reviewers. Study characteristics and secondary outcome measures will be extracted by one reviewer and randomly cross-checked by a second. Disputes between the two extractors will be resolved by consensus or the decision of a third reviewer. We will attempt to obtain missing information from supplementary files if available (such as public data repositories) or contact the authors via email.

Study characteristics extracted will include study date, study aim/objectives, setting of the study, description of participants, study design including recruitment procedure. Details of the home/community exercise intervention and the outcomes of interest including adherence will equally be extracted. In addition, the details of the descriptions of comparators for all studies will be extracted (Additional file 2). These general characteristics will be summarized and presented in a table in the results.

\section{Quality assessment}

Two reviewers will independently assess the quality of included studies. Comprehensive reporting and risk of bias in individual studies will be assessed using the Cochrane Effective Practice and Organisation of Care (EPOC) Risk of bias tool for controlled and uncontrolled before-after studies (30). The EPOC Risk of Bias tool for controlled studies assesses the quality of both randomized and non-randomized trials. The scale consists of nine items ranging from participant allocation to outcome reporting. Each criterion is rated as "unclear risk of bias" (plausible bias unlikely to seriously alter the results), "low risk of bias" (plausible bias that raise some doubt about the results), or "high risk "(plausible bias that seriously weakens confidence in the results) (30). The EPOC tool for uncontrolled before-after studies is a seven- 
item tool with criteria that ranges from intervention independence to selective outcome reporting and has similar grading to the EPOC tool for controlled trials (30). Assessments will be performed for each of the primary outcomes evaluated in the study separately. We will perform an overall assessment of risk per outcome and per study and summarize in a risk of bias table.

\section{Data analysis, assessment of heterogeneity and publication bias}

Exercise volume will be translated to metabolic equivalent (MET) hours per week based on standard definitions in the compendium of physical activities (31), to ease comparison across studies. In studies with multiple intervention groups, we shall report outcomes for all groups relative to the outcome in the minimally supervised home exercise group. Where a study reports outcome at multiple time points, we will consider the timepoints that immediately precedes and the timepoint that immediately follows the intervention in our analysis.

Continuous outcome measures will be reported as means or standardized mean differences where there are different scales for the same outcome. Where possible, missing outcomes will be computed from other reported statistics such as percentage body fat from skinfold thickness using validated formulae (32).

Where there are at least two studies with common or similar outcome measures (reported or computed) we will undertake a quantitative synthesis. We anticipate some heterogeneity in participant characteristics, study quality, sample sizes, and type and volume of exercise, hence we will assume and conduct a random effects meta-analysis. The Cochran's Q test will be used to assess for heterogeneity and the $I^{2}$ statistic to quantify it. $I^{2}$ of $0-30 \%$ will be considered minimal, $30-55 \%$ moderate, $55-75 \%$ substantial heterogeneity and $75-100 \%$ considerable heterogeneity $(33,34)$. If we find that have considerable heterogeneity across studies, we will perform a narrative synthesis.

In the event where authors report medians and interquartile ranges we will use this to compute corresponding means and standard deviations as described in previous literature (35) and perform subgroup analysis to evaluate the impact this has on effect estimates. We will perform subgroup analysis (or a narrative synthesis if insufficient studies) to compare the effect size for primary outcomes across studies with "minimal supervision" versus "no supervision”, "technology-assisted delivery" versus "no technology" as well as by type and intensity of exercise.

Sensitivity analysis will be carried out to restrict analysis to published studies, studies with low risk of bias, studies without co-interventions and studies that performed comparisons with "no exercise"; to assess the impact of these on the effect sizes. Publication bias will be evaluated using funnel plots and tested using the Egger's regression test.

Meta-analysis will be performed with the Comprehensive Meta-Analysis Software (CMA) software. Our findings will be summarized by considering the five Grading of Recommendations Assessment, 
Development and Evaluation (GRADE) criteria (study limitations, inconsistency of effect, imprecision, indirectness of evidence, and publication bias) as outlined previously (36) to determine the strength and quality of evidence for each outcome.

\section{Discussion And Conclusion}

The review will shed light on the effectiveness of self-managed home/community exercise in improving adiposity indices and hence preventing cardiometabolic complications in PLWH. We will equally demonstrate the benefits (if any) of technological assistance in such exercise programs.

In this proposal we describe how we will calculate exercise volumes for each study and hence address the variability in exercise prescription. We equally outline the steps we will take to synthesize our outcomes to arrive at meaningful comparisons. Any changes made in the methods we describe here will be documented and reported in a follow-up manuscript with our results.

Considering that a review of this kind is lacking for PLWH, we believe that our methods and eventual findings are filling an important knowledge gap. In addition to publishing our findings in a scientific journal, this work will be included in the thesis of the principal investigator and made available to the public by her institution.

\section{Abbreviations}

- HIV: Human immunodeficiency virus

- PLWH: People living with HIV.

- PROSPERO: Prospective Register of Systematic Reviews

- BMI: Body mass index

- FMl: Fat mass index

- BAl: Body adiposity index

- WHR: Waist-to-hip ratio

- VAT: Visceral adipose tissue

- CINAHL: Cumulative Index to Nursing and Allied Health Literature

- PEDro: Physiotherapy Evidence Database

- EPOC: Effective Practice and Organisation of Care

- MET: metabolic equivalent

- CMA: Comprehensive Meta-Analysis Software

- PRISMA-P: Preferred Reporting Items for Systematic reviews and Meta-analysis Protocols

- GRADE: Grading of Recommendations Assessment, Development and Evaluation

\section{Declarations}




\section{A. Ethics approval and consent to participate.}

Not applicable

\section{B. Consent for publication}

Not applicable

\section{Availability of data and materials}

Not applicable

D. Competing interests

The authors declare that they have no competing interests.

\section{E. Funding}

This study has received no funding.

\section{F. Authors' Contributions}

Study conception and design: JAA, NH, CT, and BD. Literature review: JAA. Drafting manuscript: JAA. Developing search strategy and data extraction form: JAA, NH, CT, and BD. Critical review of manuscript: $\mathrm{NH}, \mathrm{CT}$, and BD. All authors read and approved the final manuscript.

\section{G. Acknowledgments}

The authors would like to acknowledge Maria Weaver for her assistance in developing the search strategy, and Leopold N. Aminde for reviewing the manuscript.

\section{H. Amendments}

Amendments to this proposal will be documented and included in the methods section of the final output manuscript.

\section{References}

1. Samji H, Cescon A, Hogg RS, Modur SP, Althoff KN, Buchacz K, et al. Closing the Gap: Increases in Life Expectancy among Treated HIV-Positive Individuals in the United States and Canada. PloS one. 2013;8(12):e81355.

2. Sax PE, Erlandson KM, Lake JE, Mccomsey GA, Orkin C, Esser S, et al. Weight Gain Following Initiation of Antiretroviral Therapy: Risk Factors in Randomized Comparative Clinical Trials. Clinical Infectious Diseases. 2020;71(6):1379-89. 
3. Nduka CU, Uthman OA, Kimani PK, Stranges S. Body Fat Changes in People Living with HIV on Antiretroviral Therapy. AIDS Rev. 2016;18(4):198-211.

4. Feinstein MJ, Hsue PY, Benjamin LA, Bloomfield GS, Currier JS, Freiberg MS, et al. Characteristics, Prevention, and Management of Cardiovascular Disease in People Living With HIV: A Scientific Statement From the American Heart Association. Circulation. 2019;140(2):e98-124.

5. Duong M, Petit JM, Martha B, Galland F, Piroth L, Walldner A, et al. Concentration of circulating oxidized LDL in HIV-infected patients treated with antiretroviral agents: relation to HIV-related lipodystrophy. HIV Clin Trials. 2006;7(2):41-7.

6. Hsu DC, Ma YF, Hur S, Li D, Rupert A, Scherzer R, et al. Plasma IL-6 levels are independently associated with atherosclerosis and mortality in HIV-infected individuals on suppressive ART. AIDS. 2016;30(13):2065-74.

7. Borges ÁH, Silverberg MJ, Wentworth D, Grulich AE, Fätkenheuer G, Mitsuyasu R, et al. Predicting risk of cancer during HIV infection: the role of inflammatory and coagulation biomarkers. AIDS. 2013;27(9):1433-41.

8. Pourcher V, Gourmelen J, Bureau I, Bouee S. Comorbidities in people living with HIV: An epidemiologic and economic analysis using a claims database in France. PLoS One. 2020;15(12):e0243529..

9. Mdege ND, Shah S, Ayo-Yusuf OA, Hakim J, Siddiqi K. Tobacco use among people living with HIV: analysis of data from Demographic and Health Surveys from 28 low-income and middle-income countries. The Lancet Global Health. 2017;5(6):e578.

10. Quiros-Roldan E, Raffetti E, Focà E, Brianese N, Ferraresi A, Paraninfo G, et al. Incidence of cardiovascular events in HIV-positive patients compared to general population over the last decade: a population-based study from 2000 to 2012. AIDS Care. 2016;28(12):1551-8.

11. Brown TT, Cole SR, Li X, Kingsley LA, Palella FJ, Riddler SA, et al. Antiretroviral Therapy and the Prevalence and Incidence of Diabetes Mellitus in the Multicenter AIDS Cohort Study. Arch Intern Med. 2005;165(10):1179-84.

12. d’Ettorre G, Ceccarelli G, Giustini N, Mastroianni CM, Silvestri G, Vullo V. Taming HIV-Related Inflammation with Physical Activity: A Matter of Timing. AIDS Res Hum Retroviruses. 2014;30(10):936-44.

13. O’Brien KK, Tynan A-M, Nixon SA, Glazier RH. Effectiveness of aerobic exercise for adults living with HIV: systematic review and meta-analysis using the Cochrane Collaboration protocol. BMC Infectious Diseases. 2016;16:179.

14. O'Brien KK, Tynan A-M, Nixon SA, Glazier RH. Effectiveness of Progressive Resistive Exercise (PRE) in the context of HIV: systematic review and meta-analysis using the Cochrane Collaboration protocol. BMC Infectious Diseases. 2017;17(1):268.

15. Jankowski CM, Mawhinney S, Wilson MP, Campbell TB, Kohrt WM, Schwartz RS, et al. Body Composition Changes in Response to Moderate or High-Intensity Exercise Among Older Adults with 
or without HIV Infection. JAIDS Journal of Acquired Immune Deficiency Syndromes. 2020;85(3):340-5.

16. Quiles NN, Piao L, Ortiz A. The effects of exercise on lipid profile and blood glucose levels in people living with HIV: A systematic review of randomized controlled trials. AIDS Care. $2020 \mathrm{Jul}$ 2;32(7):882-9.

17. Kamitani E, Sipe TA, Higa DH, Mullins MM, Soares J. Evaluating the Effectiveness of Physical Exercise Interventions in Persons Living With HIV: Overview of Systematic Reviews. AIDS Education and Prevention. 2017 Aug 1;29(4):347-63.

18. Gomes-Neto M, Conceição CS, Carvalho VO, Brites C. A systematic review of the effects of different types of therapeutic exercise on physiologic and functional measurements in patients with HIV/AIDS. Clinics (Sao Paulo). 2013;68(8):1157-67.

19. Poton R, Polito M, Farinatti P. Effects of resistance training in HIV-infected patients: A meta-analysis of randomised controlled trials. J Sports Sci. 2017;35(24):2380-9.

20. Vancampfort D, Mugisha J, Richards J, Hert MD, Lazzarotto AR, Schuch FB, et al. Dropout from physical activity interventions in people living with HIV: a systematic review and meta-analysis. AIDS Care. 2017;29(5):636-43.

21. Schäfer AGM, Zalpour C, von Piekartz H, Hall TM, Paelke V. The Efficacy of Electronic HealthSupported Home Exercise Interventions for Patients With Osteoarthritis of the Knee: Systematic Review. J Med Internet Res. 2018;20(4):e152.

22. Li Y, Li Z, Chang G, Wang M, Wu R, Wang S, et al. Effect of Structured Home-Based Exercise on Walking Ability in Patients with Peripheral Arterial Disease: A Meta-Analysis. Annals of Vascular Surgery. 2015;29(3):597-606.

23. Anderson L, Sharp GA, Norton RJ, Dalal H, Dean SG, Jolly K, Jolly K, et al.. Home-based versus centre-based cardiac rehabilitation. Cochrane Database of Systematic Reviews 2017, Issue 6. Art. No.: CD007130. DOI: 10.1002/14651858.CD007130.pub4. Accessed 19 January 2021.

24. Roos R, Myezwa $H$, van Aswegen $H$, Musenge E. Effects of an Education and Home-Based Pedometer Walking Program on Ischemic Heart Disease Risk Factors in People Infected with HIV: A Randomized Trial. JAIDS Journal of Acquired Immune Deficiency Syndromes. 2014;67(3):268-276.

25. Agostini M, Lupo S, Palazzi J, Marconi L, Masante L. Systematized aerobic physical exercise and diet: Non-pharmacological treatment of lipodystrophy in HIV-positive patients on high-efficiency antiretroviral treatment: Dieta y ejercicio fisico aerobico sistematizado: Tratamiento no farmacologico de la lipodistrofia en pacientes VIH positivos bajo tratamiento antiretroviral de alta eficacia. Rev Med Rosario. 2009;(75):10-5.

26. Bonato M, Turrini F, De Zan V, Meloni A, Plebani M, Brambilla E, et al. A Mobile Application for Exercise Intervention in People Living with HIV. Medicine \& Science in Sports \& Exercise. 2020 Feb;52(2):425-433.

27. Cornier Marc-Andre, Després Jean-Pierre, Davis Nichola, Grossniklaus Daurice A., Klein Samuel, Lamarche Benoit, et al. Assessing Adiposity. Circulation. 2011;124(18):1996-2019. 
28. Vanltallie TB, Yang MU, Heymsfield SB, Funk RC, Boileau RA. Height-normalized indices of the body's fat-free mass and fat mass: potentially useful indicators of nutritional status. The American Journal of Clinical Nutrition. 1990;52(6):953-9.

29. Bergman RN, Stefanovski D, Buchanan TA, Sumner AE, Reynolds JC, Sebring NG, et al. A Better Index of Body Adiposity. Obesity. 2011 May 1;19(5):1083-9.

30. Cochrane Effective Practice and Organisation of Care (EPOC): EPOC Resources for review authors. epoc.cochrane.org/resources/epoc-resources-review-authors (2017). Accessed 27 Oct 2020.

31. Ainsworth BE, Haskell WL, Herrmann SD, Meckes N, Bassett DRJ, Tudor-Locke C, et al. 2011 Compendium of Physical Activities: A Second Update of Codes and MET Values. Medicine \& Science in Sports \& Exercise. 2011 Aug;43(8):1575-81.

32. Deurenberg P, Weststrate JA, Seidell JC. Body mass index as a measure of body fatness: age- and sex-specific prediction formulas. British Journal of Nutrition. 1991;65(2):105-14.

33. Higgins JPT, Thompson SG. Quantifying heterogeneity in a meta-analysis. Statistics in Medicine. 2002;21(11):1539-58.

34. Higgins JPT, Thomas J, Chandler J, Cumpston M, Li T, Page MJ, Welch VA (editors). Cochrane Handbook for Systematic Reviews of Interventions version 6.1 (updated September 2020). Cochrane, 2020. Available from www.training.cochrane.org/handbook.

35. Wan X, Wang W, Liu J, Tong T. Estimating the sample mean and standard deviation from the sample size, median, range and/or interquartile range. BMC Medical Research Methodology. 2014;14(1).

36. Guyatt GH, Oxman AD, Vist GE, Kunz R, Falck-Ytter Y, Alonso-Coello P, et al. GRADE: an emerging consensus on rating quality of evidence and strength of recommendations. BMJ. $2008 \mathrm{Apr}$ 24;336(7650):924-6.

\section{Supplementary Files}

This is a list of supplementary files associated with this preprint. Click to download.

- Additionalfile1PRISMAPchecklist.docx

- Additionalfile2DataExtractionsheet.xlsx 